\title{
Subcutaneous fat thickness, but not epicardial fat thickness, parallel weight reduction after bariatric surgery: a cardiac magnetic resonance study
} \author{
Rahul Jhaveri², Warren J Manning ${ }^{2,3}$ \\ From 16th Annual SCMR Scientific Sessions \\ San Francisco, CA, USA. 31 January - 3 February 2013
}

Murilo Foppa ${ }^{2,1^{*}}$, Kyle Pond ${ }^{2}$, Daniel D Jones ${ }^{2}$, Kraig V Kissinger ${ }^{2}$, Beth Goddu ${ }^{2}$, Benjamin Schneider ${ }^{4}$,

\section{Background}

Bariatric surgery is a very effective treatment for morbid obesity, generally improving the obesity related metabolic derangements. Epicardial fat (EPIFAT) is a visceral fat depot measurable in cardiac magnetic resonance. Changes in EPIFAT after bariatric surgery has been described, but it is not well characterized. We hypothesized that the reduction of the thoracic fat components after bariatric surgery is heterogeneous.

\section{Methods}

We analyzed since steady state free precession (SSFP) CMR data from 13 patients $(51 \pm 11$ years; $B M I=44 \pm 4 \mathrm{~kg} /$ $\mathrm{m} 2$; XX F) before and $90 \pm 13$ days after bariatric surgery (BS). Data were compared with 11 control, subjects $(65 \pm 7$ years; $\mathrm{BMI}=27.2 \mathrm{~kg} / \mathrm{m} 2$; XX F) who had two CMR exams $55 \pm 30$ days apart (CTR) but not submitted to an obesity intervention. From cine SSFP images we measured: 1) EPIFAT: mean of the maximal visceral fat thickness anterior to the epicardial surface on the right ventricular (RV) free-wall on the HLA and 4 chamber views, and the maximal fat thickness anterior to the interventricular groove on the basal short axis view, 2) Paracardial fat (PARAFAT): the fat thicknesses over the RV free-wall outside the pericardium on the HLA and 4 Chamber views, and 3) Subcutaneous fat (SUBFAT): the maximal subcutaneous fat thickness measured at the mid sternal level.

\section{Results}

Baseline and follow-up SUBFAT, PARAFAT and EPIFAT measurements for BS and CTR groups are displayed in

${ }^{2}$ Medicine (Cardiovascular Division), Beth Israel Deaconess Medical Center/ Harvard Medical School, Boston, MA, USA

Full list of author information is available at the end of the article
Table 1. At follow-up, the BS group weight declined by 18 $\pm 3.9 \mathrm{~kg}(16 \pm 3.7 \%$ of body mass). There was no body weight change in the CTR group. In the BS group, the corresponding change in the fat components were SUBFAT= $-10.1 \pm 4.7 \mathrm{~mm}(\mathrm{P}<0.001), \mathrm{PARAFAT}=-1.2 \pm 3.1 \mathrm{~mm}(\mathrm{P}=$ $0.2)$, and EPIFAT $=-0.5 \pm 1.3 \mathrm{~mm}(\mathrm{P}=0.2)$. The correlation coefficients between the fat components reduction and weight loss were SUBFAT: $r=0.63(\mathrm{P}=0.03)$, PARAFAT: $\mathrm{r}=0.64(\mathrm{P}=0.02)$, and EPIFAT: $\mathrm{r}=0.22(\mathrm{P}=0.5)$. In the CTR group, we tested the reproducibility between the two CMR studies. The intraclass correlation coefficients were higher for SUBFAT $=0.93$ and PARAFAT $=0.94$, but lower for EPIFAT $=0.35$.

\section{Conclusions}

Three months after bariatric surgery, there is a significant reduction in SUBFAT, which parallels the reduction in body weight. However, there is no significant reduction in the PARAFAT thickness. Additionally, we could not

Table 1 Fat thickeness $(\mathrm{mm})$ in bariatric surgery and control groups

\begin{tabular}{cccc}
\hline & Baseline & Follow-up & P-value \\
\hline SUBFAT & & & \\
\hline Bariatric & $33.3 \pm 9.2$ & $23.2 \pm 8.4$ & $<0.001$ \\
\hline Control & $16.5 \pm 4.5$ & $15.3 \pm 4.2$ & 0.1 \\
\hline PARAFAT & & & \\
\hline Bariatric & $11.8 \pm 2.9$ & $10.5 \pm 1.6$ & 0.2 \\
\hline Control & $9.5 \pm 3.5$ & $9.4 \pm 3.4$ & 0.4 \\
\hline EPIFAT & & & \\
\hline Bariatric & $5.8 \pm 1.7$ & $6.3 \pm 1.4$ & 0.2 \\
\hline Control & $6.3 \pm 0.9$ & $6.2 \pm 0.7$ & 0.7 \\
\hline
\end{tabular}


demonstrate significant EPIFAT reduction or relationship with weight loss.

\section{Funding}

CAPES (Brazilian Research Agency) n 9601/11.

\section{Author details}

${ }^{1}$ Cardiology, Hospital de Clinicas de Porto Alegre, Porto Alegre, Brazil. ${ }^{2}$ Medicine (Cardiovascular Division), Beth Israel Deaconess Medical Center/ Harvard Medical School, Boston, MA, USA. ${ }^{3}$ Radiology, Beth Israel Deaconess Medical Center/Harvard Medical School, Boston, MA, USA. ${ }^{4}$ Surgery, Beth Israel Deaconess Medical Center/Harvard Medical School, Boston, MA, USA.

Published: 30 January 2013

doi:10.1186/1532-429X-15-S1-E54

Cite this article as: Foppa et al:: Subcutaneous fat thickness, but not epicardial fat thickness, parallel weight reduction after bariatric surgery: a cardiac magnetic resonance study. Journal of Cardiovascular Magnetic Resonance 2013 15(Suppl 1):E54.

Submit your next manuscript to BioMed Central and take full advantage of:

- Convenient online submission

- Thorough peer review

- No space constraints or color figure charges

- Immediate publication on acceptance

- Inclusion in PubMed, CAS, Scopus and Google Scholar

- Research which is freely available for redistribution

Submit your manuscript at www.biomedcentral.com/submit
C Biomed Central 